\title{
STATUS PERIKANAN JARING TRAMEL DAN KONTRIBUSINYA TERHADAP PERIKANAN TANGKAP DI PERAIRAN PANTAI SELATAN KEBUMEN
}

\author{
Martin L. Linting") dan Agustinus Anung")
}

\begin{abstract}
ABSTRAK
Sejak dilarangnya pengoperasian pukat harimau, salah satu alat tangkap udang yang banyak digunakan nelayan adalah jaring tramel. Dalam rangka mengetahui status perikanan jaring tramel pasca pelarangan trawl dan kontribusinya terhadap perikanan tangkap, telah dilakukan per:alitian di Kebumen-Jawa Tengah pada Nopember 2000 melalui observasi di Pusat Pendaratan Ikan (PPI) Argopeni; Ayah; Kebumen dan penangkapan di laut. Hasil penelitian menunjukkan bahwa perikanan jaring trammel di daerah tersebut masih dilakukan secara tradisional. Perahu yang digunakan berukuran satu hingga dua GT dengan tenaga penggerak berkekuatan 5-15 HP. Setiap perahu umumnya mengoperasikan sekitar 20 tinting jaring. Rata-rata hasil tangkapan $2,83 \mathrm{~kg}$ udang setiap harinya. Analisis terhadap pendaratan hasil tangkapan dalam kurun waktu 5 tahun terakhir menunjukkan bahwa produksi udang dari perikanan jaring trammel rata-rata 17,43 ton dengan nilai Rp. 870,5 juta ( $38,3 \%$ dari seluruh nilai produksi perikanan tangkap) setiap tahunnya.
\end{abstract}

\begin{abstract}
Trammel net fishery and its contribution to the capture fisheries in Southern Kebumen Waters. By : Martin L. Linting and Agustinus. Anung

Since the banning of trawl fishing in accordance with Presidential Decree No.39 in 1980, trammel net one of the substitute fishing gear for shrimps which are used by traditional fishermen. In order to know the status of trammel net fishing, an observation was conducted in Argopeni-Kebumen in November 2000. The result showed that trammel net fishery is still camed out traditionally. The size of trammel net boats are between 1 and 2 GT with engine of 5-15 HP. The average number of net operated on each boat were 20 pieces of the average catch was $2,82 \mathrm{~kg}$ shrimps per day (trip). Annual average, within last five years shrimps production of trammel net fishery, was 17.43 ton worth Rp. 870.5 billion (38.3\% of total fish production value).
\end{abstract}

KEYWORDS : trammel net, contribution, capture fisheries

\section{PENDAHULUAN}

Perairan sebelah selatan Kebumen merupakan salah satu daerah di Jawa Tengah yang terletak di pantai selatan (menghadap Samudera Hindia). Di daerah ini terdapat dua Pusat Pendaratan Ikan (PPI), di mana salah satu yang terbesar adalah PPI-Argopeni. Pantai-pantai yang menghadap Samudera Hindia pada umumnya terjal, dalam, berarus kuat, dan gelombangnya tinggi, demikian pula dengan kondisi pantai di Argopeni. Sebagian dari penduduk Argopeni menggantungkan hidupnya sebagai nelayan penangkap ikan. Usaha penangkapan ikan yang dilakukan nelayan di Argopeni pada umumnya masih bersifat tradisional dan berskala kecil. Jenis alat tangkap yang dioperasikan nelayan antara lain: jaring tramel, jaring insang monofilamen, pancing rawe dasar, arad (danish seine), bubu (pot), dan pintur (crab $n e t$ ). Sejak dilarangnya pengoperasian alat tangkap pukat harimau melalui Keppres No 39 Th 1980 berbagai alat tangkap udang banyak dioperasikan nelayan. Bagi nelayan Argopeni, pelarangan pengoperasian pukat harimau tersebut berdampak positif bagi perkembangan nelayan tradisional yang sebelumnya telah ada. Sebelum dilarangnya pengoperasian pukat hariamau, perairan pantai Argopeni merupakan salah satu daerah penangkapan udang dari alat tangkap pukat harimau yang berbasis di Cilacap, sehingga selama itu keberadaan nelayan tradisional terdesak. Sejak pelarangan tersebut, ruang gerak dan peluang nelayan Argopeni untuk menangkap udang semakin terbuka.

Salah satu alat tangkap udang yang berkembang adalah jaring tramel. Menurut Nomura (1974) jaring tramel digolongkan ke dalam kelompok jaring insang dasar. Sedangkan menurut Brandt (1972), digolongkan ke dalam entangling net. Konstruksi jaring tramel terdiri dari tiga lapis (triple walled net). Dua lapis jaring di bagian luar (outer net) berukuran diameter dan mata lebih besar dari jaring lapis dalam (inner net). Konstruksi ini menyebabkan ikan atau udang yang menerobos jaring lapisan luar akan tersangkut/terperangkap pada jaring lapisan dalam yang membentuk kantong, sehingga sebagian nelayan menyebutnya 
sebagai jaring kantong. Posisi pemasangan kedua lapis jaring luar harus benar-benar simetris, sehingga jaring tramel disebut juga "mirror net" (Brandt, 1972). Sebenarnya jaring tramel di negara asalnya (Jepang) merupakan alat tangkap yang efektif untuk menangkap ikan (Matuda dan Kitahara, 1967). Dengan berbagai modifikasi (terutama ukuran bahan), jaring tramel di Indonesia digunakan untuk menangkap udang (Wudianto et al., 1988).

Penelitian ini bertujuan untuk mengetahui status perikanan jaring tramel pasca pelarangan pukat harimau di perairan Kebumen dan kontribusinya terhadap perikanan tangkap secara keseluruhan. Hasil penelitian diharapkan dapat memberikan informasi dalam upaya pengembangan perikanan pada masa mendatang.

\section{BAHAN DAN METODE}

Data primer dan sekunder yang dianalisis merupakan sebagian dari hasil observasi perikanan jaring trammel di PPI Argopeni; Ayah; Kebumen (Jawa Tengah) bulan Nopember 2000. Data primer meliputi: ukuran perahu dan konstruksi jaring tramel (melalui pengamatan dan pengukuran). Informasi mengenai metode pengoperasian alat tangkap diperoleh melalui pengamatan kegiatan operasi penangkapan di laut. Sedangkan hasil tangkapan (udang dan ikan) dilakukan secara sampling terhadap hasil tangkapan perahu jaring tramel yang didaratkan di Pusat Pendaratan Ikan Argopeni. Data sekundair meliputi: jenis dan jumlah alat tangkap serta produksinya selama periode 1996-2000.

\section{HASIL DAN BAHASAN}

\section{Perikanan Jaring Tramel}

\section{a. Perahu dan Jaring}

Jaring tramel di Argopeni dioperasikan dengan menggunakan perahu berukuran panjang $8,0-9,0$ $\mathrm{m}$, lebar 1,0-1,2 $\mathrm{m}$ dan dalam 0,7-0,8 $\mathrm{m}$ atau antara 1-2 GT. Perahu diberi alat penyeimbang, yang biasa disebut katir. Perahu terbuat dari fiberglass dan kayu. Tenaga penggerak berupa motor tempel (bahan bakar bensin) berkekuatan 15 PK dan motor diesel berkekuatan 5-7 HP dengan as (poros) baling-baling panjang. Jumlah ABK biasanya 2-3 orang. Jumiah perahu (unit penangkap) jaring trammel di Argopeni berturutturut: tahun 1996 sebanyak 154 unit, tahun 1997 sebanyak 161, tahun 1998 sebanyak 169 unit, tahun 1999 sebanyak 170 unit, dan tahun 2000 sebanyak 206 unit.

Jaring tramel yang digunakan nelayan di Argopeni mempunyai spesifikasi umum sebagai berikut: panjang jaring (tali ris atas 18 meter dan ris bawah 22 meter). Jaring lapis dalam dari bahan nilon-PA $210 \mathrm{~d}-3$, ukuran mata jaring $38 \mathrm{~mm}(1,5$ inci). Jaring lapis luar dari bahan nilon-PA $210 \mathrm{~d}-6$, ukuran mata $175 \mathrm{~mm}$ (6 inci). Rasio pengikatan(hanging ratio) (U) $55 \%$, artinya bila panjang jaring diregang adalah 100 meter dan setelah diikat menjadi 45 meter. Disain dan konstruksi jaring disajikan pada Gambar 1.

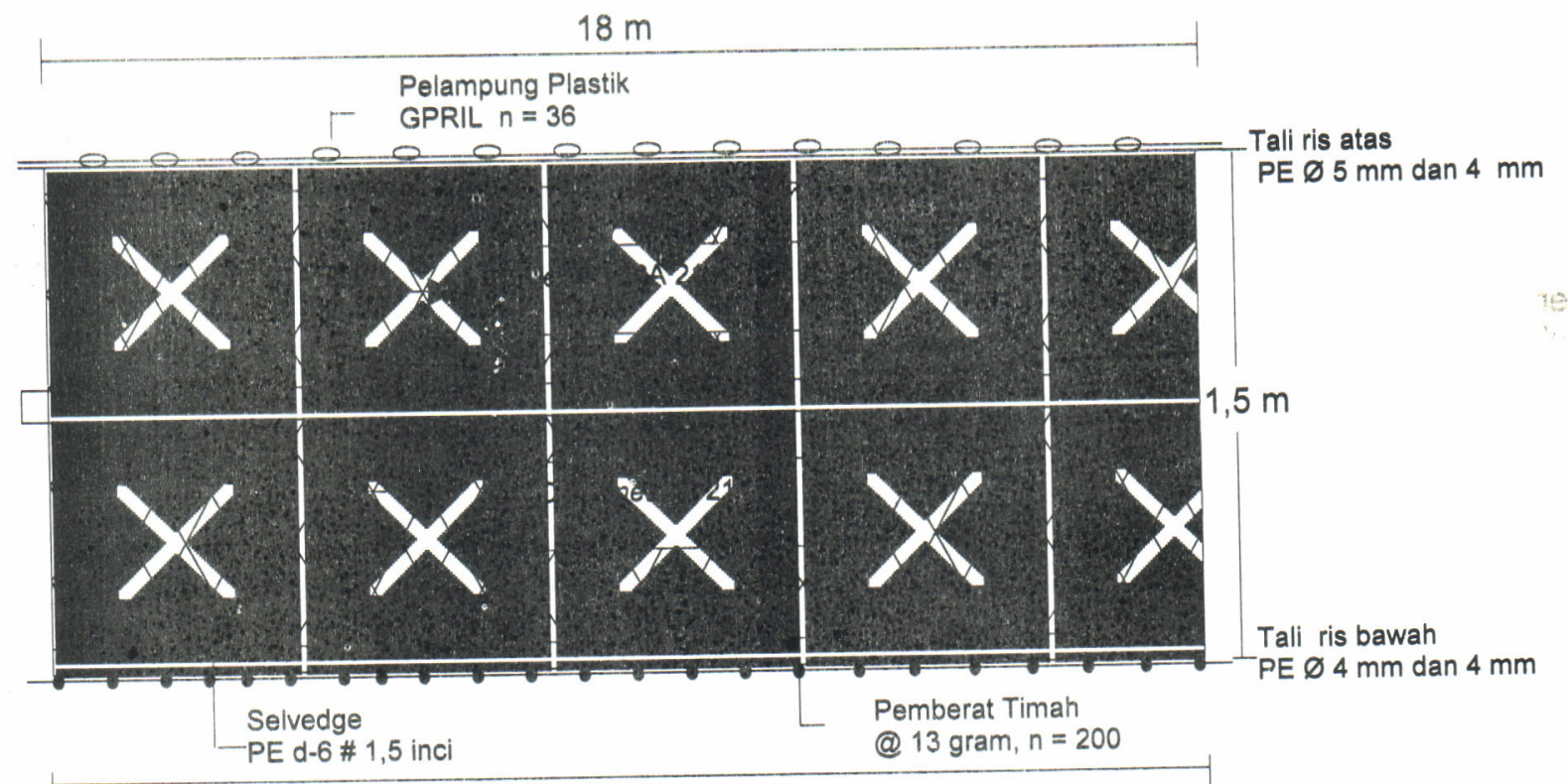

$22 \mathrm{~m}$

Gambar 1. Disain dan konstruksi umum satu pis jaring tramel di Argopeni Figure 1. General design and construction of trammel net in Argopeni 


\section{b. Daerah Penangkapan}

Daerah penangkapan jaring trammel adalah dekat pantai Argopeni, pada posisi antara $109^{\circ} 12^{\prime} \mathrm{BT}-109^{\circ} 30^{\mathrm{B}} \mathrm{BT}$ dan $7^{\circ} 42^{\prime} \mathrm{LS}-7^{\circ} 56^{\prime} \mathrm{BT}$. Dasar perairannya lumpur berpasir, datar dengan kedalaman antara 8-40 meter. Sebelum tahun 1980-an perairan ini merupakan daerah penangkapan udang kapal-kapal pukat harimau yang berpangkalan di Cilacap.

\section{c.Musim Penangkapan}

Di Argopeni, jaring tramel dapat dioperasikan sepanjang tahun dengan hasil tangkapan udang yang relatif tidak berfluktuasi tiap trip, namun jika dilihat produksi bulanannya terlihat cukup fluktuatif. Hal ini disebabkan jumlah armada yang dioperasikan tiap bulan berbeda, di mana pada musim penangkapan armada yang mengoperasikan jaring tramel lebih banyak dibandingkan bulan-bulan lainnya. Rata-rata jumiah udang yang tertangkap setiap bulan dari tiap unit tramel net disajikan pada Gambar 3. Jika dilihat dari rata-rata produksi udang yang didaratkan selama kurun waktu lima tahun (19962000), maka bulan September dan Oktober adalah terbanyak di antara bulan-bulan lainnya. Hal ini bisa dikemukakan bahwa bulan-bulan tersebut merupakan puncak musim penangkapan udang dengan jaring tramel di Argopeni.

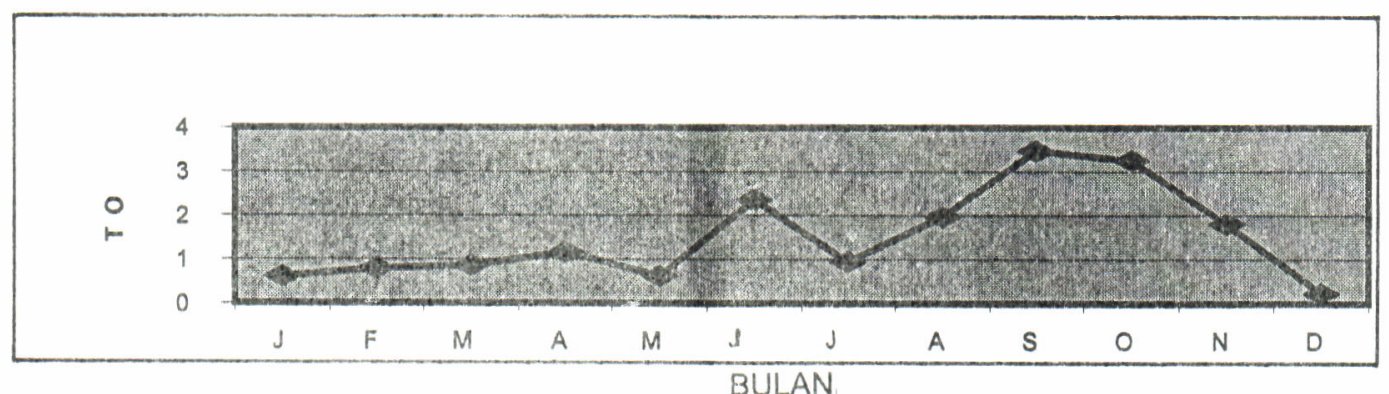

Gambar 2. Rata-rata produksi udang dari jaring tramel per bulan sepanjang tahun 1996-2000 yang didaratkan di PPI Argopeni.

Figure 2. Montly the shrimps catch average of trammel net during 1996-2000 in Argopeni.

\section{d. Teknik Penangkapan}

Satu trip penangkapan berlangsung selama satu hari di mana jaring dioperasikan pada pagisiang hari (jam 05.30-14.00). Terdapat dua metode pengoperasian jaring tramel di Argopeni, yaitu (1): jaring dihanyutkan di dasar perairan dan (2) ditarik menyapu (sweeping) di dasar perairan. Pada metode pertama dilakukan jika arus air kuat. Jaring yang telah ditawur (setting) dibiarkan menghayut terbawa arus selama sekitar dua jam. Jumlah jaring yang dioperasikan pada metoda ini mencapai 20 tinting (pis-piece). Adapun cara kedua dilakukan jika kondisi perairan tenang (arus lemah). Salah satu ujung jaring diikatkan pada buritan perahu. Kemudian perahu bergerak (dengan mesin) melingkar, sehingga jaring yang telah di set akan bergerak menyapu dasar perairan. Lama dari setiap operasi (setting-hauling) rata-rata 2 jam. Jumlah jaring yang dioperasikan pada metode ini 4-5 tinting. Setiap trip (hari) biasanya jaring dioperasikan sebanyak 3-5 kali

\section{e. Hasil Tangkapan}

Pengamatan terhadap hasil tangkapan jaring tramel yang didaratkan di PPI-Argopeni akhir bulan
November 2000 menunjukkan bahwa paling sedikit terdapat 10 jenis ikan dan udang. Hasil sampling terhadap ikan dan udang hasil tangkapan tiga perahu jaring tramel dengan total berat $184 \mathrm{~kg}$ ikan dan udang menunjukkan bahwa komposisinya sebagai berikut: udang jerbung (Penaeus merguiensis) $3 \%$, udang windu ( $P$. monodon) $1 \%$, udang krosok (Metapenaeus spp) $5 \%$, ikan kurisi (Nemipterus spp) $18 \%$, petek (Leiognathus spp) $14 \%$, kuniran (Upeneus spp) $11 \%$, bloso (Saurida spp) $11 \%$, ikan lidah (Cynoglossus spp) $10 \%$, layur (Trichiurus spp) $9 \%$, bawal hitam (Formio niger) $9 \%$ dan ikan rucah $9 \%$.

\section{h. Kemampuan Tangkap}

Tingkat keberhasilan dari alat tangkap dapat dilihat dari kemampuan tangkap (catch ability). Dari data pendaratan udang (Penaeus merguiensis dan $P$. monodon) yang tertangkap jaring tramel sepanjang tahun 1996-2000 di Argopeni berkisar $10.136,4-25.676,0 \mathrm{~kg}$ (rata-rata $17.434,2 \mathrm{~kg}$ ) yang puncaknya terjadi tahun 1998 (Tabel 1). Jumlah trip antara 3.644-10.193 (rata-rata 6.218,8) trip/tahun. Adapun kemampuan tangkap berkisar antara 2,52-3,30 (rata-rata 2,83) $\mathrm{kg} /$ trip (hari). Produksi tertinggi yang terjadi pada tahun 1998, 
yaitu $25.676 \mathrm{~kg}$ disebabkan oleh jumlah trip yang banyak, yaitu 10.193 trip. Tingginya jumlah trip penangkapan udang terjadi tahun 1998, diduga karena harga udang untuk ekspor yang cukup tinggi akibat lemahnya nilai tukar rupiah (saat itu nilai 1 US dollar mencapai Rp 15.000,-) sehingga nelayan banyak melakukan penangkapan udang.

\section{Kontribusi Terhadap Perikanan Tangkap}

Di Argopeni terdapat lima jenis alat tangkap ikan yang secara aktif dioperasikan nelayan sepanjang tahun. Produksi dari jaring tramel hanya $4,5 \%$ dari jumlah rata-rata produksi ikan yang didaratkan di TPI Argopeni. Jumlah tersebut menempati urutan ke empat dari rata-rata produksi masing-masing alat lainnya (Tabel 2). Namun jika dilihat dari nilai uang yang dihasilkan, ternyata jaring tramel menempati urutan teratas, yaitu $38,3 \%$ (Tabel 3). Hal ini dapat dimengerti, sebab hasil tangkapan jaring tramel adalah berupa udang yang mempunyai harga tinggi.

Tabel 1. Produksi udang, jumlah trip dan kemampuan tangkap jaring tramel sepanjang tahun 19962000 di Argopeni

Table 1. Shrimps production, number of trip and catchability of trammel net in 1996-2000 in Argopeni

\begin{tabular}{|c|c|c|c|c|c|}
\hline $\begin{array}{l}\text { Tahun } \\
\text { (Year) }\end{array}$ & 1996 & 1997 & 1998 & 1999 & $2000^{*}$ \\
\hline \multicolumn{6}{|l|}{ Item } \\
\hline Produksi / Production (kg) & 10136,4 & 19995,7 & 25676,0 & 20832,6 & 10530,5 \\
\hline Rerata / Average (kg/bulan) & 844,7 & 1666,3 & 2139,7 & 1736,1 & 1053,1 \\
\hline Jumlah Trip / Total Trip & 4020,0 & 6066,0 & 10193,0 & 7131,0 & 3644,0 \\
\hline Rerata / Average (trip/bulan) & 335,0 & 505,5 & 849,4 & 594,2 & 364,4 \\
\hline Jumlah Kapal / Total Ship (unit) & 154,0 & 161,0 & 169,0 & 170,0 & 206,0 \\
\hline $\begin{array}{l}\text { Kemampuan tangkap / Catch Ability } \\
\text { (kg/trip/unit) }\end{array}$ & 2,52 & 3,30 & 2,52 & 2,92 & 2,90 \\
\hline $\begin{array}{l}\text { Hanya sampai bulan OK } \\
\text { "Only to October }\end{array}$ & & $\begin{array}{l}\text { Sumber } \\
\text { Source }\end{array}$ & PI Argopeni & $\begin{array}{l}\text { diolah) } \\
\text { ized data) }\end{array}$ & \\
\hline
\end{tabular}

Tabel 2. Produksi ikan dan udang dari masing-masing alat tangkap sepanjang tahun 1996-2000 di TPI Argopeni

Table 2. Fish and shrimps production of each fishing gear in 1996-2000 in Argopeni.

\begin{tabular}{|c|c|c|c|c|c|c|c|}
\hline Alat Tangkap & 1996 & 1997 & 1998 & 1999 & 20007 & Rataan & $\%$ \\
\hline $\begin{array}{l}\text { Jaring Insang } \\
\text { Jaring Tramel") }\end{array}$ & $\begin{array}{r}124194,2 \\
10136,4\end{array}$ & $\begin{array}{r}164877,2 \\
19995.7\end{array}$ & $\begin{array}{l}99665,0 \\
25676,0\end{array}$ & $\begin{array}{l}96799,6 \\
20832,6\end{array}$ & $\begin{array}{r}103274,6 \\
10530,5\end{array}$ & $\begin{array}{r}117750,1 \\
17434.2\end{array}$ & $\begin{array}{r}30,8 \\
4,5\end{array}$ \\
\hline Pancing Rawe & 27257,0 & 40302,5 & 21135,6 & 34409,7 & 81213,5 & 40862,4 & 10,7 \\
\hline Arad & 118282,1 & 256714,8 & 66266,9 & 328702,6 & 201426,3 & 194278,5 & 50,8 \\
\hline Bintur & 4387,5 & 24274,0 & 4387,5 & 4179,5 & 29513,5 & 12628,4 & 3,2 \\
\hline Jumlah & 277135,5 & 507138,2 & 221016,5 & 485875,0 & 425958,4 & 382691,6 & 100 \\
\hline
\end{tabular}

Tabel 3. Nilai Produksi (rupiah) ikan dan udang dari masing-masing alat tangkap sepanjang tahun 1996-2000 di TPI Argopeni

Table 3. Production value (rupiah) of fish and shrimp of each gear in 1996-2000 in Argopeni

\begin{tabular}{|c|c|c|c|c|c|c|c|}
\hline & & & & & & \multicolumn{2}{|c|}{ Unit : (x 1000 rupiah) } \\
\hline Alat Tangkap & 1996 & 1997 & 1998 & 1999 & $2000^{\prime}$ & Rataan & $\%$ \\
\hline Jr. Insang & 498025 & 209157 & 988844 & 884876 & 989134 & 676359 & 29,7 \\
\hline Jr.Trammel") & 49691 & 439606 & 1716855 & 1335504 & 811337 & 870598 & 38,3 \\
\hline Pc. Rawe & 35688 & 95568 & 75827 & 147154 & 387953 & 148438 & 6,5 \\
\hline Arad & 202973 & 591286 & 139188 & 1433139 & 378614 & 549040 & 24,1 \\
\hline Bintur & 4387 & 13954 & 4387 & 69021 & 61115 & 30573 & 1,4 \\
\hline Jumlah & 790767 & 1349574 & 2925102 & 3737256 & 2628155 & 2286171 & 100 \\
\hline
\end{tabular}




\section{KESIMPULAN}

Dari data dan informasi di atas dapat disimpulkan sebagai berikut:

1. Salah satu alat tangkap udang yang cukup penting peranannya di Kabupaten Kebumen adalah jaring tramel. Alat tangkap ini masih dioperasikan secara tradisional dengan sistem trip harian. Kemampuan tangkap rata-rata sebesar $2,83 \mathrm{~kg} /$ trip dengan jumlah tawur rata-rata sebanyak 3 kali/trip dan jumlah jaring 20 tinting/tawur. Musim puncak penangkapan adalah bulan SeptemberNovember. Perikanan jaring tramel mempunyai kontribusi yang cukup penting terhadap perikanan tangkap di Kebumen. Hal ini ditunjukkan dengan peranannya yang cukup dominan dibanding jenis perikanan lainnya di daerah tersebut yaitu: perikanan jaring tramel produksinya mencapai 17,43 ton udang dengan nilai Rp.870,6 juta per tahun. Nilai tersebut menempati urutan pertama terhadap nilai produksi perikanan tangkap lainnya.

2. Jenis ikan dan udang yang tertangkap jaring tramel berdasarkan komposisi beratnya di Argopeni meliputi: udang jerbung (Penaeus merguiensis) $3 \%$, udang windu ( $P$. monodon) $1 \%$, udang krosok (Metapenaeus spp) $5 \%$, ikan kurisi (Nemipterus sp) $18 \%$, petek (Leiognatus spp) $14 \%$, kuniran (Upeneus spp) $11 \%$, bloso (Saurida spp) $11 \%$, ikan lidah (Cynoglossus spp) 10\%, layur (Trichiurus spp)
$9 \%$, bawal hitam (Formio niger) $9 \%$ dan ikan rucah $9 \%$.

\section{DAFTAR PUSTAKA}

Brandt. A.V., (1972). Fish Catching Methods of the World, Fishing News (Books) Ltd, 110 Fleet Street, London, EC 4,pp.158-165/204-214.

Koike,A. and K.Matuda, 1988. Catching Efficiency of Slackness and Mesh Size of Inner Net. Nipon Suisan gakkaishi, 54. (2): 221-227.

Matuda, K. and T.Kitahara, 1967. On the Estimation of Catching Efficiency of Sweeping Trammel Net. Bulletin of Japanese society of scientific fisheries, 33 (12):1096-1098.

Nomura, M. 1974 Gillnet Fishery, Japanese fishing gear and methods. Texbook for marine fisheries research course, OTCA, Government of Japan, pp. 103-130.

Puslitbangkan, 1991. Perikanan Jaring Trammel dan Jaring Arad, Paket Teknologi Perikanan. Jakarta. p.19.

Wudianto, A. Anung, dan Ch. Nasution. 1988. Pengaruh Penggunaan Benang Monofilament dan Multifilament sebagai Bahan Jaring Lapis Tiga (Trammel Net) menurut Letak terhadap Hasil Tangkapan Udang Jerbung (Penaeus merguiensis). Jurnal Penelitian Perikanan Laut, 48: 83-91. 
